\title{
Azithromycin increases phagocytosis of apoptotic bronchial epithelial cells by alveolar macrophages
}

\author{
S. Hodge, G. Hodge, S. Brozyna, H. Jersmann, M. Holmes and P.N. Reynolds
}

ABSTRACT: Chronic obstructive pulmonary disease (COPD) is associated with increased apoptosis and defective phagocytosis in the airway. As uncleared cells can undergo secondary necrosis and perpetuate inflammation, strategies to improve clearance would have therapeutic significance. There is evidence that the 15-member macrolide antibiotic azithromycin has antiinflammatory properties. Its effects may be increased in the lung due to its ability to reach high concentrations in alveolar macrophages (AMs).

The present study investigated the effects of low-dose $\left(500 \mathrm{ng} \cdot \mathrm{mL}^{-1}\right)$ azithromycin on the phagocytosis of apoptotic bronchial epithelial cells and neutrophils by AMs. Flow cytometry was applied to measure phagocytosis and receptors involved in AM recognition of apoptotic cells. Cytokines were investigated using cytometric bead array.

Baseline phagocytosis was reduced in COPD subjects compared with controls. Azithromycin significantly improved the phagocytosis of epithelial cells or neutrophils by AMs from COPD subjects by 68 and $38 \%$, respectively, often up to levels comparable with controls.

The increase in phagocytosis was partially inhibited by phosphatidylserine, implicating the phosphatidylserine pathway in the pro-phagocytic effects of azithromycin. Azithromycin had no effect on other recognition molecules (granulocyte-macrophage colony-stimulating factor, CD44, CD31, CD36, CD91, av33 integrin). At higher doses, azithromycin decreased levels of proinflammatory cytokines. Thus, low-dose azithromycin therapy could provide an adjunct therapeutic option in chronic obstructive pulmonary disease.

KEYWORDS: Alveolar macrophage, apoptosis, azithromycin, chronic obstructive pulmonary disease, phagocytosis

$\mathrm{n}$ the normal airway, repair of injury and resolution of inflammation are highly regulated processes. Epithelial injury exposes portions of the basement membrane. A provisional matrix, derived from plasma proteins including fibrin and fibronectin, is rapidly formed. Simultaneously, airway epithelial cells de-differentiate, proliferate and accumulate over the denuded area. Although the cellular mechanisms for removal of excess epithelial cells have not been fully elucidated, the process is likely to involve apoptosis (programmed cell death) of cells not attached to the basement membrane followed by phagocytic removal of apoptotic fragments by neighbouring alveolar macrophages (AMs). This process avoids secondary necrosis and the release of cell contents that may promote further inflammation [1, 2]. In addition to their critical role in the phagocytosis of epithelial cells, AMs play an important role in the removal of exogenous particles, such as bacteria, and of excess inflammatory cells including neutrophils.

Previous studies have shown that chronic obstructive pulmonary disease (COPD) is associated with increased apoptosis of bronchial epithelial cells [3]. If these cells are not efficiently cleared by adjacent AMs, an accumulation of apoptotic and necrotic material may ensue, promoting the ongoing inflammation and loss of structural integrity that is prevalent in COPD. This may result, at least partially, from an overwhelming of the clearance capacity of AMs, either by excess apoptosis, or by a functional deficiency in the AM. In this regard, the current authors have also reported defective phagocytosis of bronchial epithelial cells by AMs in COPD [4]. Building on this evidence, the authors' current research has focused on treatment strategies that aim specifically at improving

\section{AFFILIATIONS}

Dept of Thoracic Medicine, Royal Adelaide Hospital and Lung Research Laboratory, Hanson Institute,

Adelaide, Australia.

CORRESPONDENCE

S. Hodge

Lung Research

Hanson Institute

Frome Rd

Adelaide

5001

South Australia

Fax: 61881616043

E-mail: sandy.hodge@imvs.sa.gov.au

Received:

January 042006

Accepted after revision:

May 152006

SUPPORT STATEMENT

The present study was funded by a National Health and Medical Research Council (NHMRC) Project Grant, an NHMRC Clinical Career Development Award, an Allen \& Hanburys

Respiratory Research Fellowship and a Royal Adelaide Hospital Clinical

Project Grant.

European Respiratory Journal

Print ISSN 0903-1936

Online ISSN 1399-3003 
macrophage function with a view to improving clearance of apoptotic material in the lung.

A number of studies have suggested that macrolide antibiotics, including azithromycin, have anti-inflammatory properties, partly due to their modulation of production of pro-inflammatory cytokines $[5,6]$. In addition, a few studies have reported increased macrophage phagocytic activity in the presence of these antibiotics (using neutrophils or beads as targets) $[7,8]$. However, the effect of macrolide antibiotics on phagocytosis of apoptotic bronchial epithelial cells by AMs, particularly with regard to COPD, has not been studied previously.

The current study investigated the effect of the 15-member macrolide antibiotic azithromycin on the phagocytic ability of AMs obtained from bronchoalveolar lavage (BAL) from human volunteers. It was hypothesised that low-dose azithromycin would improve the phagocytic function of AMs for apoptotic bronchial epithelial cells. Such an approach has the potential to complement existing therapies for COPD significantly.

\section{MATERIALS AND METHODS}

\section{Bronchoscopy}

AMs were collected from 10 healthy volunteers and nine subjects with COPD (diagnosed using the Global Initiative for Chronic Obstructive Lung Disease criteria [9] of a relevant history and post-bronchodilator forced expiratory volume in one second (FEV1) $30-80 \%$ of predicted and FEV1/forced vital capacity $<70 \%$ ), using BAL obtained at fibreoptic bronchoscopy, as previously described [3, 4]. Volunteers were specifically recruited for the study and informed consent was obtained. Control subjects were never-smokers with the exception of one currently smoking subject who had normal lung function and no evidence of lung disease. Six COPD subjects were current smokers and three ex-smokers. There was no exacerbation of COPD for 6 weeks prior to involvement in the study. Two of the COPD subjects were receiving inhaled corticosteroids, a further two used bronchodilators as required and the remaining subjects were untreated. Lung cancer was excluded by radiological examination (at least plain posteroanterior and lateral chest radiography) and bronchoscopic examination. Demographic details of the subjects are presented in table 1. Ethics approval was obtained from the Royal Adelaide Hospital (Adelaide, Australia). AMs were washed and resuspended in RPMI 1640 media (Gibco, Karlsruhe, Germany), supplemented with $10 \%$ foetal calf serum (Gibco) and $1 \%$ weight/volume penicillin/streptomycin (Gibco; hereinafter referred to as "culture medium"), at a concentration of $3 \times 10^{5}$ cells $\cdot \mathrm{mL}^{-1}$ for investigation of phagocytosis and $3 \times 10^{6}$ cells $\cdot \mathrm{mL}^{-1}$ for all other investigations.

\section{Reagents}

Azithromycin was purchased from Pfizer Inc. (New York, NY, USA) and clindamycin from Upjohn Co. (Tokyo, Japan). Ampoules for intravenous use were reconstituted with distilled water to $100 \mathrm{mg} \cdot \mathrm{mL}^{-1}$ and $150 \mathrm{mg} \cdot \mathrm{mL}^{-1}$, respectively, then diluted to the required concentrations with RPMI 1640. The following monoclonal antibodies (MABs) and immunological reagents were employed: CD45 (phycoerythrin (PE)CY5), CD14 (PE-CY5), CD33 (PE-CY5), CD36 (fluorescein isothiocyanate; FITC), CD51 (FITC; Immunotech/Coulter,
Marseille, France), Annexin V (FITC; BD Biosciences, San Jose, CA, USA), 7-amino-actinomycin D (7-AAD; Sigma Chemicals, Castle Hill, Australia), CaspACE FITC-VAD-FMK (Promega, Madison, WI, USA), Mitotracker green (MTG; Molecular Probes, Eugene, OR, USA), CD61 (PE) and CD44 (FITC; BD Biosciences), CD31 (platelet/endothelial cell adhesion molecule-1; PECAM) and CD91 (low-density lipoprotein receptor-related protein; Serotec, Oxford, UK). A MAB to granulocyte-macrophage colony-stimulating factor (GM-CSF) receptor, (MAB)4HI (GM-CSF-R), was provided by A. Lopez (Hanson Institute, Adelaide, Australia). A control immunoglobulin (Ig)G MAB (BD Biosciences) and PE-conjugated rat antimouse IgG1 (BD Biosciences) were used with (MAB)4HI. (MAB)217 (IgM kappa chain, a gift from P. Henson, University of Colorado Health Sciences Center, Denver, CO, USA) was also used to identify a surface receptor (expressed on transforming growth factor- $\beta$ and $\beta$-glycan stimulated human monocyte-derived macrophages) that recognises phosphatidyl serine (PS) on apoptotic cells. A control IgM MAB and FITCconjugated goat anti-mouse IgM (Rockland Immunochemicals, Gilbertsville, PA, USA) were used with the (MAB)217.

\section{Stimulation of AMs}

AMs were incubated with different concentrations of azithromycin or the 16-member macrolide antibiotic clindamycin, as a negative control, for $24 \mathrm{~h}$ at $37^{\circ} \mathrm{C}$ in an atmosphere of $5 \% \mathrm{CO}_{2}$. GM-CSF was used as a positive control based on reports that it up-regulates phagocytosis in several other models [10, 11]. After 24-h incubation, the supernatant was removed and stored at $-70^{\circ} \mathrm{C}$ for further analysis. The pellet containing AMs was resuspended, and surface staining and investigation of apoptosis carried out immediately.

\section{HBE bronchial epithelial cells}

Immortalised normal human bronchial epithelial (HBE) cells (cell line 16HBE) were used as phagocytic targets. The cell line was maintained and passaged as previously described [12]. For use in the phagocytosis assay, the cells were induced to apoptosis using ultraviolet (UV) radiation for $20 \mathrm{~min}$, then stained with MTG as previously described [12]. It has previously been shown that induction of apoptosis with UV for $20 \mathrm{~min}$ achieved $>80 \%$ apoptosis with minimal necrosis, as assessed by Annexin V/propidium iodide staining, more consistently than other methods including Fas ligation [12].

\section{Neutrophil isolation}

Neutrophils were isolated from the peripheral blood of healthy human donors by dextran sedimentation and density-gradient centrifugation. The neutrophil layer was washed in PBS and contaminating erythrocytes lysed with $0.9 \%$ buffered ammonium chloride for $5 \mathrm{~min}$. Neutrophils were again washed and resuspended in culture medium at a concentration of $5 \times 10^{6}$ cells $\cdot \mathrm{mL}^{-1}$, then incubated for $24-48 \mathrm{~h}$ at $37^{\circ} \mathrm{C}$ in $5 \% \mathrm{CO}_{2}$ and assessed for apoptosis using Annexin V staining as previously described [13]. The percentage of apoptotic neutrophils deemed suitable for use in the phagocytosis assay was $\geqslant 60 \%$.

\section{Phagocytosis of apoptotic airway epithelial cells and neutrophils by AMs}

A flow-cytometric assay to measure phagocytosis was applied, as previously reported [13], with minor modifications. Briefly, 


\begin{tabular}{lcc} 
TABLE 1 & $\begin{array}{l}\text { Demographic characteristics of the population } \\
\text { studied }\end{array}$ & CoPD \\
\hline Subjects $\mathbf{n}$ & 10 & 9 \\
Age yrs & $51 \pm 16$ & $55 \pm 9$ \\
Smoking pack-yrs & $4 \pm 11$ & $36 \pm 8^{*}$ \\
FEV1 \% pred & $106.2 \pm 14$ & $69.8 \pm 18^{*}$ \\
BAL recovery mL & 71 & $52^{*}$ \\
FEV1 \% FVC & $89.4 \pm 15$ & $56.3 \pm 11^{*}$ \\
\hline & & \\
Data are presented as mean \pm SD unless otherwise stated. COPD: chronic \\
obstructive pulmonary disease; FEV1: forced expiratory volume in one second; \\
\% pred: percentage of predicted; BAL: bronchoalveolar lavage; FVC: forced \\
vital capacity. *: significant difference from control group, p<0.05.
\end{tabular}

BAL aliquots $(1 \mathrm{~mL})$ were added to $10-\mathrm{mL}$ polypropylene tubes (Johns Professional Products, Sydney, Australia), on a $45^{\circ}$ slope, and incubated for $2 \mathrm{~h}$ at $37^{\circ} \mathrm{C} / 5 \% \mathrm{CO}_{2}$. The fluid was removed and the adherent AMs were reincubated for $24 \mathrm{~h}$ in $1 \mathrm{~mL}$ of culture medium containing azithromycin, clindamycin or GM-CSF (a control with medium alone was included). All treatments and controls were performed in triplicate. The fluid was gently removed from the adherent AM monolayer. MTGstained apoptotic bronchial epithelial cells or neutrophils were washed and then repelleted in $1 \mathrm{~mL}$ of culture medium containing the required concentrations of azithromycin or other treatment. These were added to the AMs at a ratio of 10:1. After 1.5-h incubation, the fluid was gently removed, the cells exposed to ice-cold $0.5 \mathrm{mM}$ EDTA, then pelleted by centrifugation without further washing. AMs were then stained with CD33 (PE-Cy5) MAB and washed. Unfixed cells were analysed immediately using a FACS Calibur flow cytometer (BD Biosciences). Crystal violet $\left(0.8 \mathrm{mg} \cdot \mathrm{mL}^{-1}\right)$ was added to quench autofluorescence of AMs and adherent but not phagocytosed epithelial cells. The current authors have previously shown that these assay conditions are optimal for detection of phagocytosis, with an intra-assay coefficient of variation of $10.6 \%$.

\section{Effect of azithromycin on viability of AMs and bronchial epithelial cells}

Annexin $\mathrm{V}$ staining

Staining with Annexin V was performed for bronchial epithelial cells as previously described [13]. Annexin staining could not be used for the investigation of AM apoptosis owing to the known expression of PS from ingested apoptotic cells on the AM cell membrane.

\section{7-AAD staining}

Staining with 7-AAD was used to quantify apoptosis as previously described [13].

\section{Staining of apoptotic cells for active caspases}

CaspACE FITC-VAD-FMK, an FITC-conjugate of the cellpermeable caspase inhibitor valine-alanine-aspartic acid-fluoromethyl ketone, allows delivery of the inhibitor into the cell where it binds to caspase, serving as a marker for apoptosis.
Cells were stained with $100 \mu \mathrm{l}$ of $10-\mu \mathrm{M}$ CaspACE, followed by staining with CD14 to identify the macrophage population as previously described [14].

\section{Effect of azithromycin on pro-inflammatory cytokine production by AMs}

Interleukin (IL)-12, tumour necrosis factor (TNF)- $\alpha$, IL-10, IL-6, IL-1 $\beta$ and IL- 8 were quantified using an Inflammatory Cytometric Bead Array kit and software (BD Biosciences) as previously reported [15].

\section{Effect of azithromycin on receptors responsible for the phagocytosis of apoptotic bronchial epithelial cells by AMs} The effects of azithromycin on receptors important in the recognition of apoptotic cells by AM were investigated. These included the thrombospondin receptor (TSP-R, CD36), the avß3 integrin (CD51/CD61), CD31, CD91 and (MAB)217reactive PS receptor. A control $\operatorname{IgM} \operatorname{MAB}\left(100 \mu \mathrm{g} \cdot \mathrm{mL}^{-1}\right)$ was used as the control for (MAB)217. In concert with the analysis of phagocytic function, expression of these receptors on AMs in the presence of azithromycin was quantified using flowcytometric methods as previously reported [4]. In view of the current authors' findings and reports by others [16] of the enhancement of phagocytic function by engagement of the CD44 receptor on AMs, the effects of azithromycin on AM expression of CD44 were also investigated.

\section{Effect of azithromycin on GM-CSF receptor expression and GM-CSF production by AMs}

In view of the current authors' findings of increased phagocytosis in the presence of GM-CSF, the effects of azithromycin on GM-CSF levels and GM-CSF receptor expression by AMs were investigated. GM-CSF receptor levels were determined using a MAB to GM-CSF receptor ((MAB) $4 \mathrm{HI})$ and flow-cytometric methods as described previously. A control IgG MAB (Dako, Glostrup, Denmark) was included with each analysis. MABS were used at a final concentration of $1 \mu \mathrm{g} \cdot \mathrm{mL}^{-1}$.

GM-CSF concentrations were measured by specific ELISA (Quantikine; R\&D Systems, Minneapolis, MN, USA), using 24$\mathrm{h}$ supernatant from AMs cultured in the presence/absence of $500 \mathrm{ng} \cdot \mathrm{mL}^{-1}$ azithromycin (this concentration was based on the lowest concentration of azithromycin that significantly increased the phagocytic ability of AMs). Triplicate samples from nine individual donors were stored at $-70^{\circ} \mathrm{C}$ and tested on the same day.

\section{Inhibition of phagocytosis by PS liposomes and CD44}

AMs $\left(3 \times 10^{6}\right.$ cells $\cdot \mathrm{mL}^{-1}$ in a total volume of $\left.100 \mu \mathrm{L}\right)$ were preincubated with each inhibitor at $37^{\circ} \mathrm{C}$ for $30 \mathrm{~min}$, followed by washing and assay of phagocytosis as described previously. The inhibitors were MABs to CD44 (Serotec) used at a concentration of $10 \mu \mathrm{g} \cdot \mathrm{mL}^{-1}$, and liposomes prepared by sonication of pure phosphotidylcholine (Avanti Polar Lipids, Pelhan, AL, USA) and PS (Avanti Polar Lipids) in PBS at a molar ratio of 70:30, used at a concentration of $0.1 \mathrm{mM}$ total lipid [17].

\section{Statistical analysis}

The nonparametric Mann-Whitney U-test was used to analyse data. A p-value of $<0.05$ was considered significant. 


\section{RESULTS}

\section{BAL return}

There was significantly reduced BAL return in asymptomatic smokers and COPD subjects (table 1). However, adequate AM numbers to perform the investigations described were obtained from both groups. It should be noted that not all investigations were performed on all subjects.

\section{Effect of macrolide antibiotics on phagocytosis of apoptotic bronchial epithelial cells and neutrophils by AMs}

Treatment with $500 \mathrm{ng} \cdot \mathrm{mL}^{-1}$ of azithromycin significantly increased the percentage of AMs that had phagocytosed apoptotic bronchial epithelial cells, compared with untreated AMs (figs 1 and 2). For control subjects, treatment of AMs with
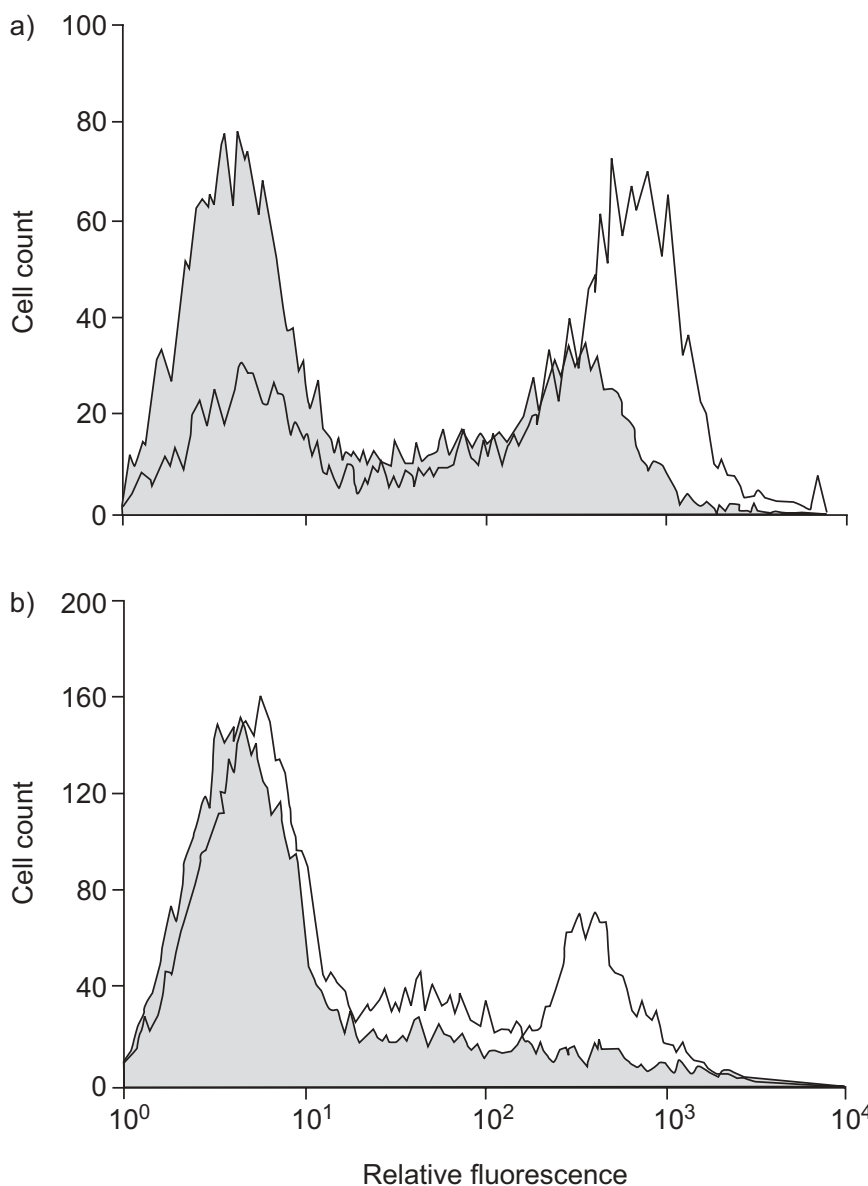

FIGURE 1. Representative histograms showing the effects of azithromycin on the phagocytosis of apoptotic bronchial epithelial cells and neutrophils by alveolar macrophages (AM; derived from normal volunteers). AMs were incubated with $500 \mathrm{ng} \cdot \mathrm{mL}^{-1}$ azithromycin for $24 \mathrm{~h}$ prior to phagocytosis assay. The percentage of AMs that had ingested fluorescein isothiocyanate-stained apoptotic cells after 90 min co-incubation was assessed by flow cytometry. Histograms show relative fluorescence intensities of Mitotracker green staining of a) AM plus ingested apoptotic bronchial epithelial cells, and b) AM plus ingested apoptotic neutrophils. There is relatively lower phagocytosis of apoptotic neutrophils compared with apoptotic epithelial cells. The peaks to the left represent AMs that have not ingested cells; the peaks to the right represent AMs that have ingested cells. 1 : untreated cells; — : azithromycin-treated cells.
$500 \mathrm{ng} \cdot \mathrm{mL}^{-1}$ azithromycin resulted in a mean $55 \%$ increase. Similarly, for COPD subjects, there was a mean $67 \%$ increase in phagocytosis compared with no-agents-added control. These results were noted for both current and ex-smoker COPD subjects, and for the two COPD subjects who were treated with inhaled corticosteroids.

Consistent with the results obtained using apoptotic airway epithelial cells, there was a significant increase (mean increase 38 and $70 \%$ in control and COPD groups, respectively) in phagocytosis of apoptotic neutrophils in the presence of $500 \mathrm{ng} \cdot \mathrm{mL}^{-1}$ azithromycin (figs 1 and 2 ).

There was no significant increase in phagocytosis with increasing doses of azithromycin beyond $500 \mathrm{ng} \cdot \mathrm{mL}^{-1}$ (fig. 3). Similar enhancing effects were noted in the presence of $500 \mathrm{IU} \cdot \mathrm{mL}^{-1} \mathrm{GM}-\mathrm{CSF}$, a positive control (for control subjects, treatment of AMs with GM-CSF resulted in a $65 \%$ increase in phagocytosis of bronchial epithelial cells compared with noagents-added control). In contrast, a 16-member macrolide, clindamycin, failed to improve the phagocytic ability of AMs significantly and was thereafter used as a negative control (fig. 3).

The effects of azithromycin were dependent on the length of time the AMs were pre-incubated with the antibiotic (fig. 4). Pre-incubation of airway epithelial cells or neutrophils with azithromycin did not improve their phagocytosis by AMs (data not shown).

\section{Baseline phagocytic ability of macrophages from COPD subjects versus controls}

The phagocytic capacity of the macrophages from COPD subjects was lower than that seen with the normal controls $(p=0.005)$, providing confirmation of previous results [13], on this occasion in a cohort of subjects in whom malignancy had been excluded (fig. 2).

\section{Effect of azithromycin on viability of AMs and bronchial epithelial cells}

7-AAD staining and measurement of caspase activation revealed no significant effects on AM viability of $500 \mathrm{ng} \cdot \mathrm{mL}^{-1}$ azithromycin for up to $48 \mathrm{~h}$, compared with control treatment (data not shown). Similarly, treatment with azithromycin for up to $48 \mathrm{~h}$ did not adversely effect the viability of $16 \mathrm{HBE}$ bronchial epithelial cells compared with control treatment where no azithromycin was added (e.g. $500 \mathrm{ng} \cdot \mathrm{mL}^{-1}$ azithromycin for $24 \mathrm{~h}$. Annexin: control $21.5 \pm 5.7 \%$ versus azithromycin 25.8 $\pm 9.1 \%$; 7-AAD: control $24.5 \pm 5.7 \%$ versus azithromycin $24.6 \pm 7.9 \%$; Caspase: control $25.3 \pm 4.5 \%$ versus azithromycin $23.4 \pm 5.1 \%$ ).

\section{Effect of azithromycin on AM phenotype and receptors responsible for the phagocytosis of apoptotic bronchial epithelial cells by AMs}

There was no change in CD14 staining on AMs in the presence of azithromycin (data not shown). The $\alpha v \beta 3$ integrin/TSP-R/ TSP system is one pathway by which AMs recognise apoptotic cells [18]. Levels of these receptors on AMs were measured to investigate their involvement in the effects of azithromycin on phagocytosis. No significant differences in expression of TSP-R (CD36) or $\alpha \mathrm{v} \beta 3$ integrin were noted in the presence of 


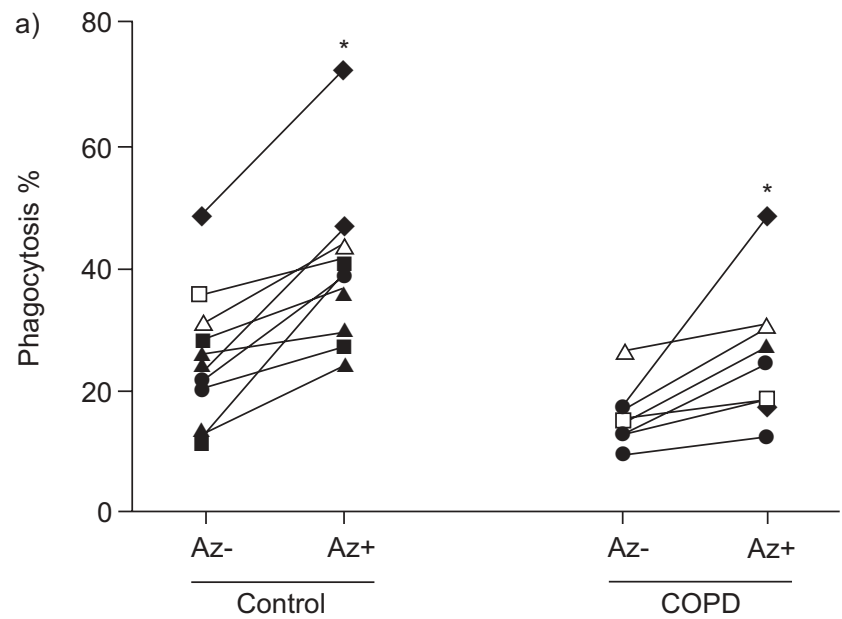

b)

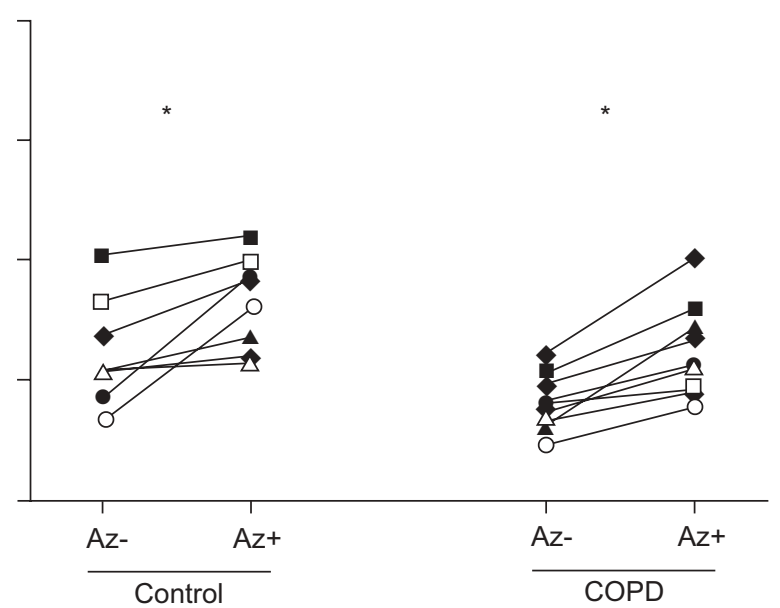

FIGURE 2. Effect of azithromycin (500 ng $\left.\cdot \mathrm{mL}^{-1}\right)$ on the phagocytosis of apoptotic a) bronchial epithelial cells, and b) neutrophils by alveolar macrophages (AMs). AMs from normal volunteers or subjects with chronic obstructive pulmonary disease (COPD) were incubated with (Az+)/without (Az-) $500 \mathrm{ng} \cdot \mathrm{mL}^{-1}$ azithromycin for $24 \mathrm{~h}$ prior to phagocytosis assay. Each value represents the mean of triplicate determinations. ${ }^{*}: p<0.05$ versus control with no azithromycin added.

$500 \mathrm{ng} \cdot \mathrm{mL}^{-1}$ azithromycin (fig. 5). The expression of CD51 and CD61 was low on AMs and not increased in the presence of azithromycin. Similarly, there was no change in the expression of (MAB)217-reactive receptor, which recognises PS on apoptotic cells, after treatment of AM with azithromycin (fig. 5). CD31 and CD91, two further receptors on AMs that are involved in the recognition of apoptotic cells, were also investigated. No significant differences in the expression of CD31 or CD91 were noted in the presence of $500 \mathrm{ng} \cdot \mathrm{mL}^{-1}$ azithromycin (fig. 5).

\section{Effect of azithromycin on GM-CSF receptor expression and GM-CSF production by AMs}

The expression of GM-CSF receptor on AMs was low $(<10 \%$ of cells) and not significantly increased in the presence of $500 \mathrm{ng} \cdot \mathrm{mL}^{-1}$ azithromycin for $24 \mathrm{~h}$.

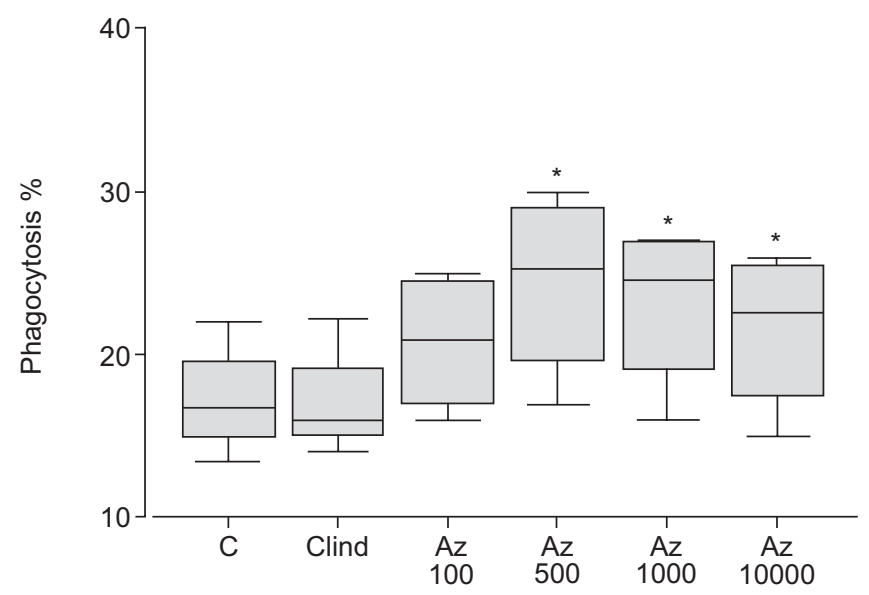

FIGURE 3. Effects of clindamycin (Clind) and varying concentrations of azithromycin (Az; 0-10,000 $\mathrm{ng} \cdot \mathrm{mL}^{-1}$ ) on the phagocytosis of apoptotic bronchial epithelial cells by alveolar macrophages (AMs). AMs from normal volunteers were incubated with azithromycin for $24 \mathrm{~h}$ prior to phagocytosis assay. Box plots show mean $\pm S D$ and data range of three separate experiments. *: $p<0.05$ versus control (C) with no antibiotic added.
There was no significant increase in GM-CSF production by AMs after $24 \mathrm{~h}$ in the presence of $500 \mathrm{ng} \cdot \mathrm{mL}^{-1}$ azithromycin (no azithromycin $6.8 \pm 9.2 \mathrm{pg} \cdot \mathrm{mL}^{-1}$ versus $500 \mathrm{ng} \cdot \mathrm{mL}^{-1}$ azithromycin $7.0 \pm 10.8 \mathrm{pg} \cdot \mathrm{mL}^{-1}$ ). For all receptors, similar results were observed in the presence of 1,000 or $5,000 \mathrm{ng} \cdot \mathrm{mL}^{-1}$ azithromycin (data not shown).

\section{Inhibition of phagocytosis by PS liposomes and CD44}

Azithromycin and CD44 ligation had similar phagocytosisenhancing effects (fig. 6). There was no additional increase in phagocytosis when the two were combined.

PS liposomes suppressed azithromycin-enhanced phagocytosis (fig. 6), indicating that the PS pathway may be at least partially involved in the azithromycin-mediated phagocytosis of apoptotic bronchial epithelial cells by AMs.

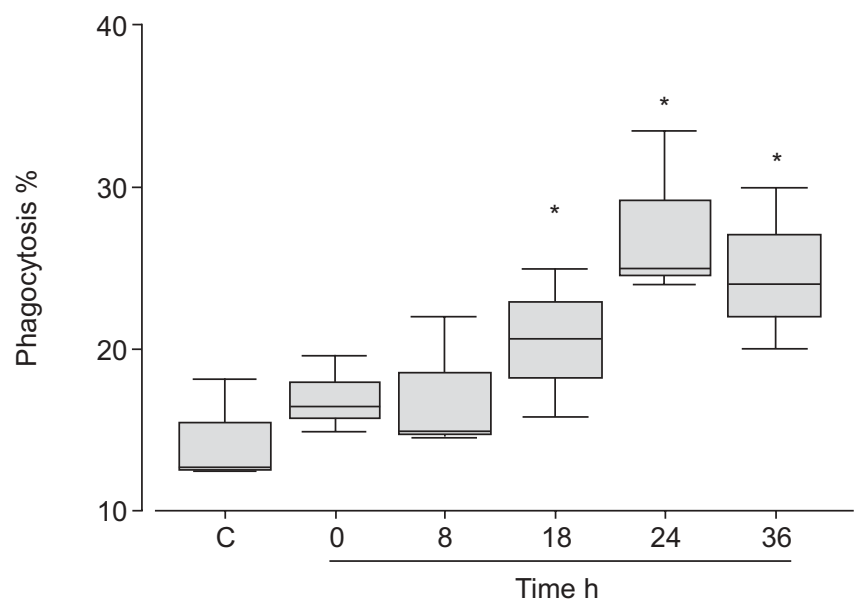

FIGURE 4. Time-dependent effects of pre-incubation of alveolar macrophages (AMs) with $500 \mathrm{ng} \cdot \mathrm{mL}^{-1}$ azithromycin on the phagocytosis of apoptotic bronchial epithelial cells by AMs. AMs from normal volunteers were incubated with azithromycin for $0-36 \mathrm{~h}$ prior to phagocytosis assay. Box plots show mean $\pm \mathrm{SD}$ and data range of three separate experiments. ${ }^{*}: p<0.05$ versus control $(C)$ with no azithromycin added. 

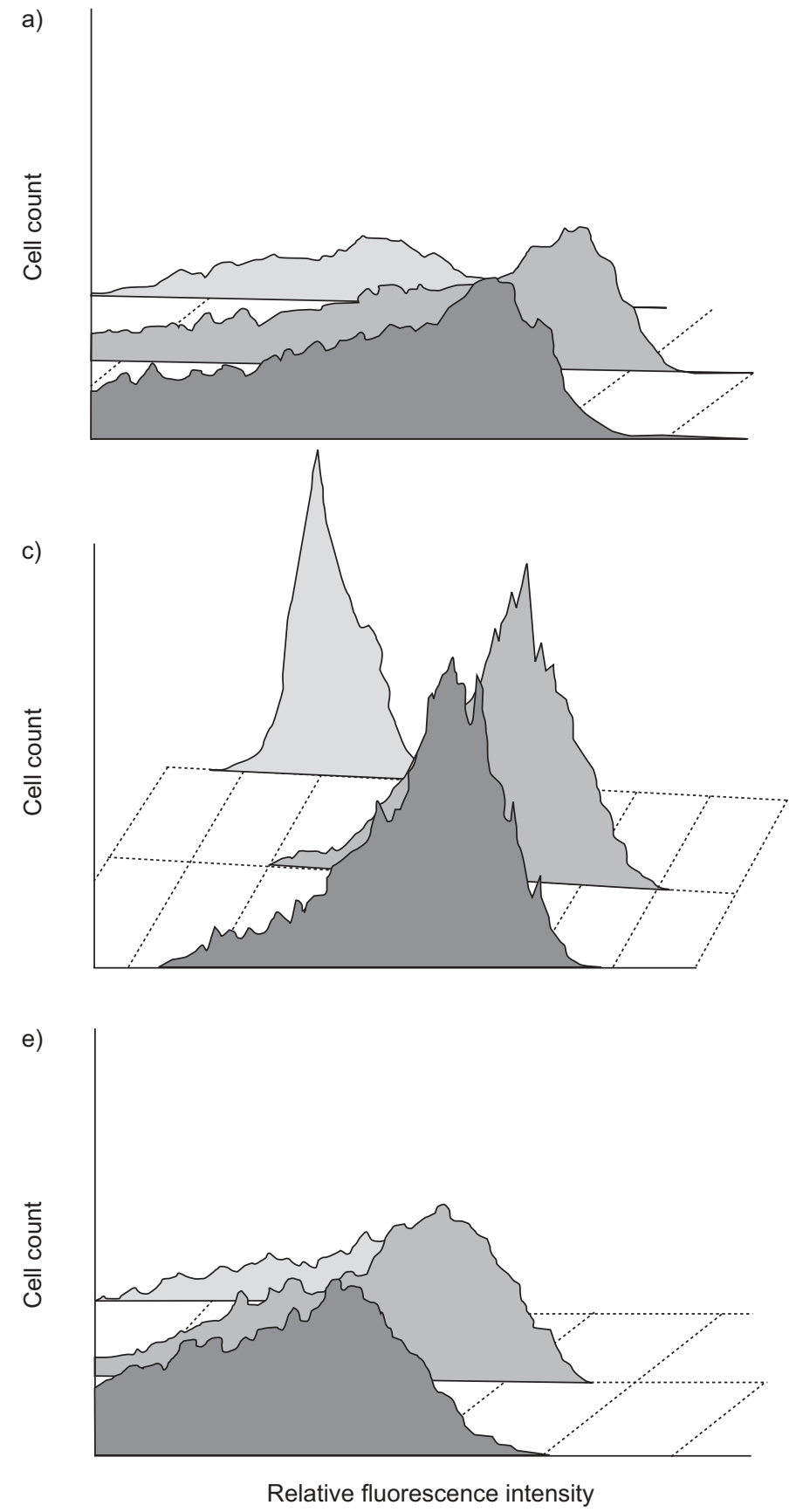

\section{Effect of azithromycin on pro-inflammatory cytokine production by AMs}

Cytokine levels were measured by cytometric bead array after 24-h incubation of AMs in the presence of azithromycin. With $500 \mathrm{ng} \cdot \mathrm{mL}^{-1}$ azithromycin, there was a trend for decreased expression of IL-6 and significantly reduced expression of TNF- $\alpha$ and IL-8 (fig. 7). However, the decrease reached statistical significance only when concentrations of azithromycin were increased to $1,000 \mathrm{ng} \cdot \mathrm{mL}^{-1}$ for $\mathrm{TNF}-\alpha$ and $10,000 \mathrm{ng} \cdot \mathrm{mL}^{-1}$ for IL-8 (fig. 7).

\section{DISCUSSION}

The current authors report that the macrolide antibiotic azithromycin at low doses significantly improved the b)

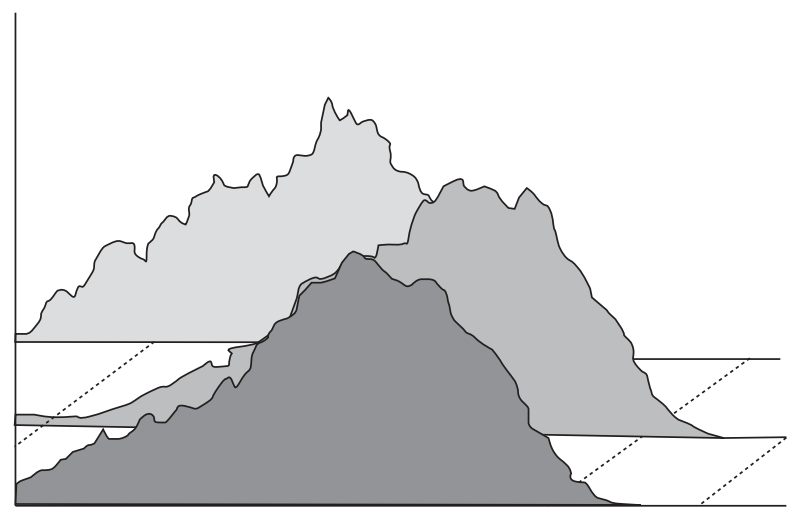

d)

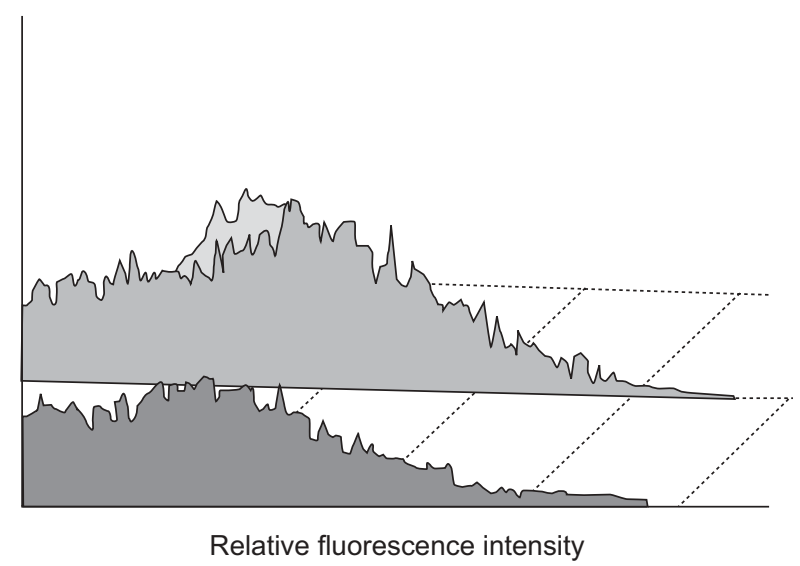

FIGURE 5. Detection of phagocytic recognition molecules on alveolar macrophages (AMs). AMs were incubated for $24 \mathrm{~h}$ in the presence $(\square) /$ absence ( $\square$ ) of $500 \mathrm{ng} \cdot \mathrm{mL}^{-1}$ azithromycin, and flow cytometry was used to measure surface staining. AMs were gated as CD33 (PE-Cy5) bright. Histograms show relative fluorescence intensities of surface staining for a) CD44, b) CD91, c) monoclonal antibody 217-reactive phosphatidylserine receptor, d) CD36, and e) CD31. There were no significant changes in the presence of $500 \mathrm{ng} \cdot \mathrm{mL}^{-1}$ azithromycin. ${ }^{1}$ : isotype control.

phagocytosis of apoptotic bronchial epithelial cells by BALderived AMs from normal and COPD subjects, without having pro-apoptotic effects on either AMs or epithelial cells. No changes were noted in the presence of a 16-member macrolide, clindamycin. In agreement with other studies [7, 8], similar effects were also noted for clearance of apoptotic neutrophils. These results were noted for both current and ex-smoker COPD subjects, and for the two COPD subjects who were treated with inhaled corticosteroids, suggesting that the prophagocytic effects of azithromycin are not adversely influenced by smoking per se, or by drug effects. Whether the effects of azithromycin are reduced in patients with advancing age remains to be determined. The present study investigated subjects with mean ages of 53 and $60 \mathrm{yrs}$ for controls and 

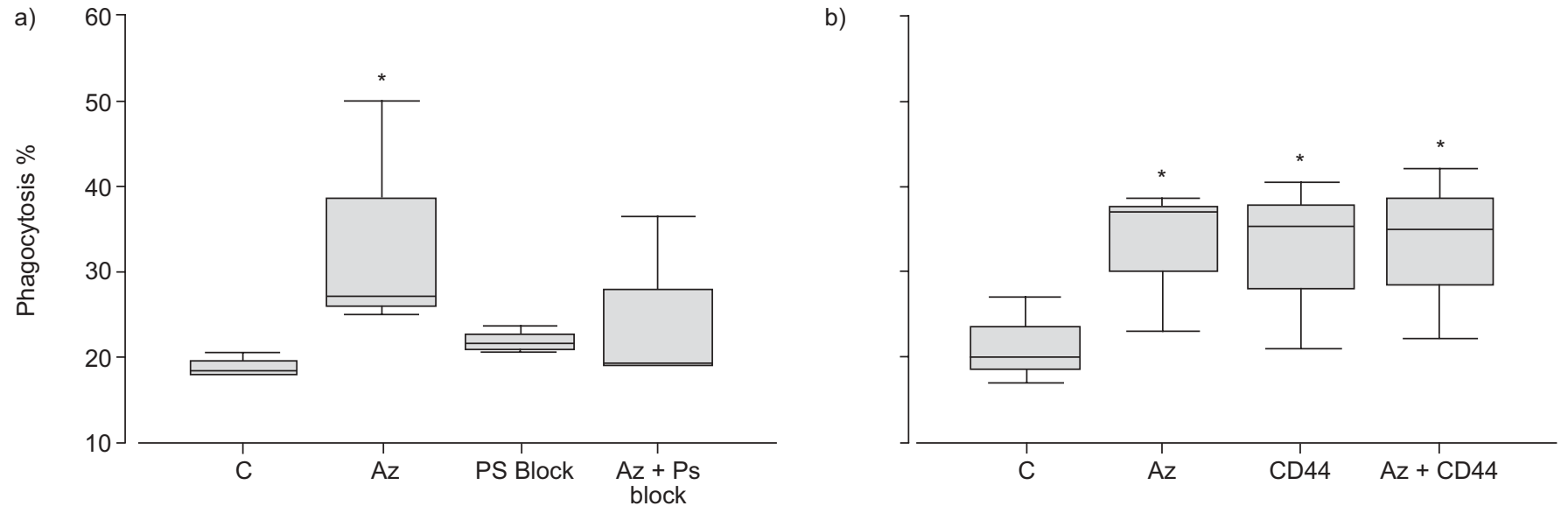

FIGURE 6. Effect of inhibitors on the phagocytosis of apoptotic bronchial epithelial cells by alveolar macrophages (AMs). AMs from normal volunteers were incubated with each inhibitor for $30 \mathrm{~min}$, washed then exposed to apoptotic bronchial epithelial cells for $90 \mathrm{~min}$. a) phosphatidylserine (PS) liposomes; b) $\mathrm{CD}_{4}$ (10 $\left.\mu \mathrm{g} \cdot \mathrm{mL}^{-1}\right)$. C: $\mathrm{media}$ only; Az: azithromycin $500 \mathrm{ng} \cdot \mathrm{mL}^{-1}$; PS block: $0.1 \mathrm{mM}$ PS liposomes. Box plots show mean $\pm \mathrm{sD}$ and data range of three separate experiments. *: $p<0.05$ versus control with no inhibitor or Az added. There is an increase in the phagocytic ability of AMs with CD44 ligation or Az but no additive effect with both mediators. There is a decrease in the pro-phagocytic effect of azithromycin after treatment with PS liposomes.

COPD groups, respectively. Although the effects of ageing upon human AMs have not been determined, a study of rodent macrophages reported age-related changes in macrophage function [19].

Improving the phagocytic ability of AMs for bronchial epithelial cells may have clinical significance with regard to new or adjunct treatments for COPD where there is inflammation associated with ineffective repair of the injured epithelium and loss of structural integrity. This inflammatory condition is associated with increased apoptosis of bronchial and alveolar epithelial cells [3]. In addition to an absolute increase in proapoptotic mechanisms, the current authors have previously shown that impaired capacity for phagocytic clearance of apoptotic bronchial epithelial cells is likely to be important in COPD [12]. There is already compelling experimental evidence that macrophages play a key role in the resolution of inflammatory responses. For instance, the causative link between macrophage dysfunction and consequent accumulation of secondary necrotic material was demonstrated in a study by KNAPP et al. [2], in which mice selectively depleted of AMs showed impaired resolution of inflammation and increased mortality, directly related to increased accumulation of apoptotic material and secondary necrosis.

The current findings of improved AM phagocytic ability for apoptotic bronchial epithelial cells in the presence of azithromycin may thus provide a novel approach to supplement existing therapies in COPD. To date, pharmacological therapies for COPD have focused on smooth-muscle function (bronchodilators) and efforts to dampen inflammatory responses (corticosteroids). Refinements in these approaches have yielded some therapeutic gains but, in many patients, responses are still often unsatisfactory. It has also become clear that many of the cellular abnormalities in COPD, including excess epithelial apoptosis, persist despite smoking cessation [3]. Thus, novel approaches to treatment are critical if management of this disease is to improve. Therapies that improve clearance of accumulated apoptotic material may reduce the risk of secondary necrosis and release of toxic cell contents that perpetuate inflammation.

The pharmokinetics of azithromycin are characterised by rapid uptake by AMs with high, sustained levels in tissues [20, 21]. The effects of azithromycin may be even more marked in COPD subjects who continue to smoke as smokers have increased intrapulmonary uptake of antibiotics that are highly concentrated in AMs [22, 23]. Importantly, there have been many reports of the anti-inflammatory properties of azithromycin $[24,25]$. As a result, low-dose azithromycin has already been used for clinical trials in various disease states, including cystic fibrosis [26], panbronchiolitis [27] and bronchiolitis obliterans [22]. In addition, an in vivo study of human volunteers treated with $500 \mathrm{mg} \cdot$ day $^{-1}$ azithromycin for 3 days demonstrated an increase in neutrophil apoptosis up to 28 days after the last azithromycin dose, and a continuous fall in chemokine and IL-6 concentrations in serum [28]. This finding has particular relevance to COPD where prolonged neutrophil survival has been linked to the pathogenesis of the disease [29].

The current findings suggest that the effects of azithromycin may be mediated by improved phagocytic ability of AMs for apoptotic bronchial epithelial cells, in addition to other antiinflammatory properties of the antibiotic. The findings are consistent with those of YAMARYO et al. [7], who reported that azithromycin promoted the phagocytosis of apoptotic neutrophils by AMs. The mechanisms leading to the improvement of AM phagocytosis in the presence of low-dose azithromycin are unclear. Consistent with other studies [30], the current authors noted a significant decrease in TNF- $\alpha$ and IL- 8 in the presence of azithromycin. However, these effects required higher concentrations of azithromycin $\left(>1,000 \mathrm{ng} \cdot \mathrm{mL}^{-1}\right)$ than the maximum effect on phagocytosis $\left(500 \mathrm{ng} \cdot \mathrm{mL}^{-1}\right)$, suggesting that the pro-phagocytic effects of low-dose azithromycin may involve pathways other than those related to the inflammatory cytokine/chemokine network. 

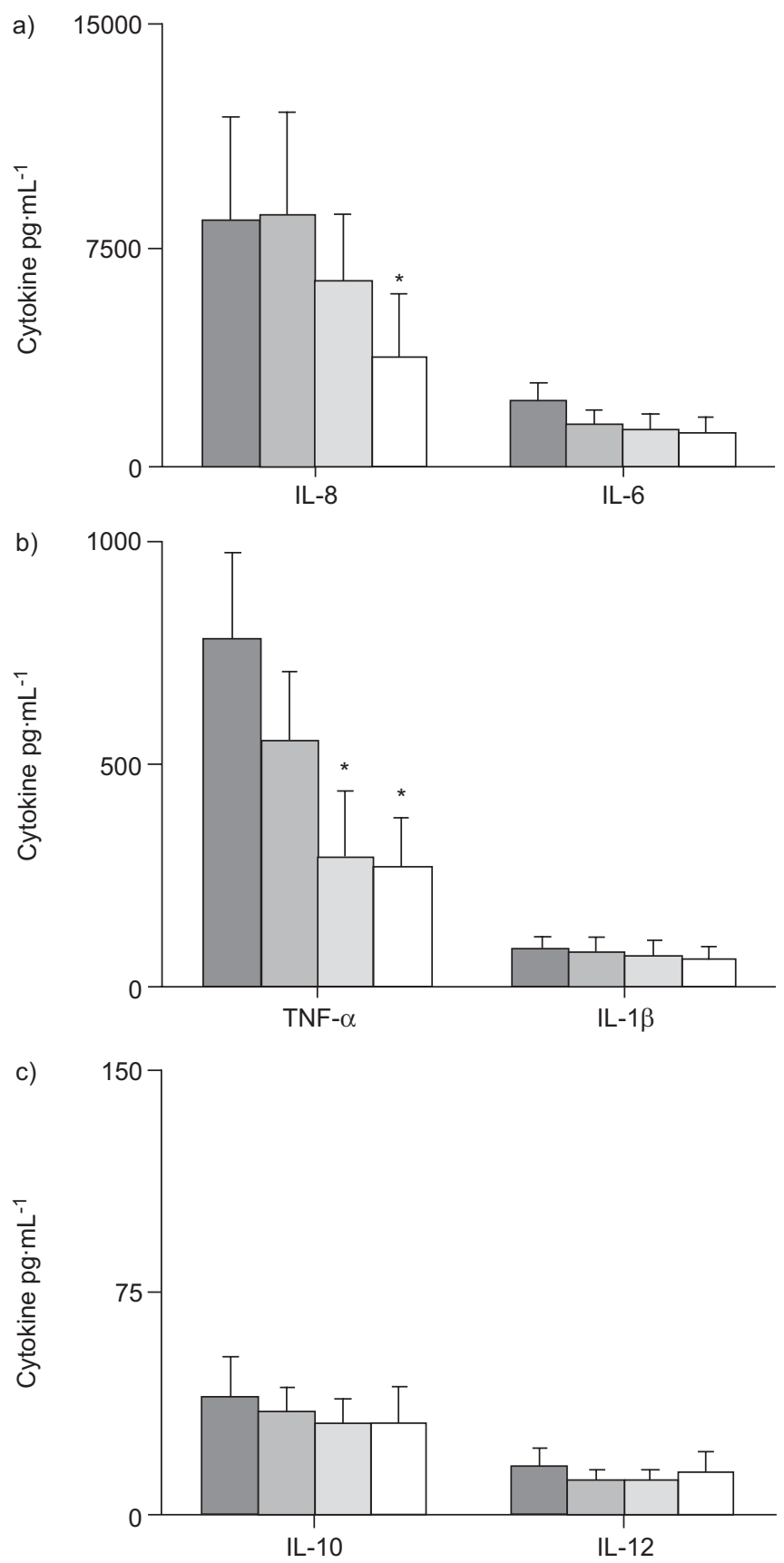

FIGURE 7. Effect of azithromycin on pro-inflammatory cytokine production by alveolar macrophages (AMs). Azithromycin (500-10,000 $\left.\mathrm{ng} \cdot \mathrm{mL}^{-1}\right)$ was added to AMs for $24 \mathrm{~h}$. Cytokine levels in culture supernatant were measured by cytometric bead array. There is a significant decrease in tumour necrosis factor (TNF)- $\alpha$ in the presence of 1,000 and $10,000 \mathrm{ng} \cdot \mathrm{mL}^{-1}$ azithromycin and interleukin (IL)-8 in the presence of $10,000 \mathrm{ng} \cdot \mathrm{mL}^{-1}$ azithromycin. Data are presented as mean \pm SEM of five separate experiments, in triplicate. $\mathbf{\square}$ : control (no azithromycin); $\mathbf{\square}: 500 \mathrm{ng} \cdot \mathrm{mL}^{-1}$ azithromycin; $\quad \square: 1,000 \mathrm{ng} \cdot \mathrm{mL}^{-1}$ azithromycin; $\square: 10,000 \mathrm{ng} \cdot \mathrm{mL}^{-1}$ azithromycin. $*: p \leqslant 0.05$ versus control.

Ligation of CD44 receptors was shown to increase the phagocytic ability of AMs by a similar magnitude to azithromycin. However, the effects of azithromycin and CD44 ligation on phagocytosis were not additive. While the latter finding may implicate the CD44 pathway in the pro-phagocytic effects of azithromycin, it is also possible that the maximum phagocytic capacity of the AMs had been reached, masking the additive effect that would have been noted if azithromycin was working via a separate pathway to CD44. Additionally, no change in AM surface expression of CD44 in response to azithromycin was found.

Several receptors important for the recognition and removal of apoptotic cells by AMs were studied. These include the vitronectin receptor ( $\alpha \mathrm{v} \beta 3$ integrin), TSP-R (CD36), CD31 (PECAM), CD91 and a (MAB)217-reactive PS receptor [31, 32]. In the present study, however, no changes were noted in any of these receptors in the presence of azithromycin. YAMARYO et al. [7] similarly found that blocking AMs with (MAB)217 did not alter the levels of phagocytosis of apoptotic neutrophils by AMs. The present study found, however, that PS liposomes inhibited the azithromycin-enhanced phagocytosis of apoptotic bronchial epithelial cells by AMs, indicating that the pro-phagocytic ability of azithromycin is at least partially PS dependent. These findings are also consistent with a report of PS receptor-dependent up-regulated phagocytosis of apoptotic neutrophils in the presence of erythromycin and clarythromycin [7]

YAMASAWA et al. [33] recently investigated the effects of azithromycin on TNF- $\alpha$-stimulated A549 airway epithelial cells and reported that the mechanism of action of azithromycin may, at least partially, relate to the modulation of GM-CSF release. However, the increase in GM-CSF only occurred in the presence of azithromycin at concentrations $>10,000 \mathrm{ng} \cdot \mathrm{mL}^{-1}$. The current authors used azithromycin at concentrations that are clinically achievable with low-dose treatment regimes [34] and found no significant changes in GM-CSF release or expression of GM-CSF receptor after treatment of AMs with azithromycin, suggesting that the GM-CSF pathway may not be involved in the effects of low-dose azithromycin on AM function.

Although commonly used for treatment of acute exacerbations, there are little data on the use of low-dose long-term azithromycin therapy for COPD, although another macrolide antibiotic, clarithromycin (at $500 \mathrm{mg} \cdot \mathrm{day}^{-1}$ for 3 months), has been applied for the treatment of patients with moderate-tosevere COPD [35], causing a small reduction in the neutrophil differential and neutrophil chemotaxis. Whether low-dose long-term azithromycin treatment will result in a significant improvement in COPD requires further study. Interestingly, the present study showed that the phagocytosis-promoting effects of azithromycin reached their maximum at the low dose of $500 \mathrm{ng} \cdot \mathrm{mL}^{-1}$, suggesting that the low doses used in cystic fibrosis trials would be appropriate for improving the phagocytic ability of AMs in COPD.

The current authors have thus established the efficacy of azithromycin for improving macrophage function in normal and chronic obstructive pulmonary disease subjects. This work indicates a rationale for further clinical studies of azithromycin in chronic obstructive pulmonary disease.

\section{ACKNOWLEDGEMENTS}

The authors acknowledge the invaluable contribution of the Bronchoscopy Unit and the nursing staff at the Chest Clinic of 
the Thoracic Medicine Dept, Royal Adelaide Hospital, Adelaide, Australia.

\section{REFERENCES}

1 Hart SP, Haslett C, Dransfield I. Recognition of apoptotic cells by phagocytes. Experientia 1996; 52: 950-956.

2 Knapp S, Leemans JC, Florquin S, et al. Alveolar macrophages have a protective antiinflammatory role during murine pneumococcal pneumonia. Am J Respir Crit Care Med 2003; 167: 171-179.

3 Hodge S, Hodge G, Holmes M, Reynolds PN. Increased airway epithelial and T-cell apoptosis in COPD remains despite smoking cessation. Eur Respir J 2005; 25: 447-454.

4 Hodge SJ, Hodge GL, Holmes M, Reynolds PN. Flow cytometric characterization of cell populations in bronchoalveolar lavage and bronchial brushings from patients with chronic obstructive pulmonary disease. Cytometry B Clin Cytom 2004; 61: 27-34.

5 Uriarte SM, Molestina RE, Miller RD, et al. Effect of macrolide antibiotics on human endothelial cells activated by Chlamydia pneumoniae infection and tumor necrosis factor-alpha. J Infect Dis 2002; 185: 1631-1636.

6 Khan AA, Slifer TR, Araujo FG, Remington JS. Effect of clarithromycin and azithromycin on production of cytokines by human monocytes. Int J Antimicrob Agents 1999; 11: 121-132.

7 Yamaryo T, Oishi K, Yoshimine H, Tsuchihashi Y, Matsushima K, Nagatake T. Fourteen-member macrolides promote the phosphatidylserine receptor-dependent phagocytosis of apoptotic neutrophils by alveolar macrophages. Antimicrob Agents Chemother 2003; 47: 48-53.

8 Xu G, Fujita J, Negayama K, et al. Effect of macrolide antibiotics on macrophage functions. Microbiol Immunol 1996; 40: 473-479.

9 Pauwels RA, Buist AS, Ma P, Jenkins CR, Hurd SS. Global strategy for the diagnosis, management, and prevention of chronic obstructive pulmonary disease: National Heart, Lung, and Blood Institute and World Health Organization Global Initiative for Chronic Obstructive Lung Disease (GOLD): executive summary. Respir Care 2001; 46: 798-825.

10 Paine R, Preston AM, Wilcoxen S, et al. Granulocytemacrophage colony-stimulating factor in the innate immune response to Pneumocystis carinii pneumonia in mice. I Immunol 2000; 164: 2602-2609.

11 Kedzierska K, Mak J, Mijch A, et al. Granulocyte-macrophage colony-stimulating factor augments phagocytosis of Mycobacterium avium complex by human immunodeficiency virus type 1-infected monocytes/macrophages in vitro and in vivo. J Infect Dis 2000; 181: 390-394.

12 Hodge S, Hodge G, Scicchitano R, Reynolds PN, Holmes M. Alveolar macrophages from subjects with chronic obstructive pulmonary disease are deficient in their ability to phagocytose apoptotic airway epithelial cells. Immunol Cell Biol 2003; 81: 289-296.

13 Hodge GL, Flower R, Han P. Optimal storage conditions for preserving granulocyte viability as monitored by Annexin $\mathrm{V}$ binding in whole blood. J Immunol Methods 1999; 225: 27-38.

14 Hodge S, Hodge G, Reynolds PN, Holmes M. Differential rates of apoptosis in bronchoalveolar lavage and blood of lung transplant patients. J Heart Lung Transplant 2005; 9: 1305-1314.

15 Hodge G, Hodge S, Haslam R, et al. Rapid simultaneous measurement of multiple cytokines using 100 microl sample volumes - association with neonatal sepsis. Clin Exp Immunol 2004; 137: 402-407.

16 Vivers S, Heasman SJ, Hart SP, Dransfield I. Divalent cation-dependent and -independent augmentation of macrophage phagocytosis of apoptotic neutrophils by CD44 antibody. Clin Exp Immunol 2004; 138: 447-452.

17 Fadok VA, Voelker DR, Campbell PA, Cohen JJ, Bratton DL, Henson PM. Exposure of phosphatidylserine on the surface of apoptotic lymphocytes triggers specific recognition and removal by macrophages. J Immunol 1992; 148: 2207-2216.

18 Fadok VA, Savill JS, Haslett C, et al. Different populations of macrophages use either the vitronectin receptor or the phosphatidylserine receptor to recognize and remove apoptotic cells. J Immunol 1992; 149: 4029-4035.

19 Kohut ML, Senchina DS, Madden KS, Martin AE, Felten DL, Moynihan JA. Age effects on macrophage function vary by tissue site, nature of stimulant, and exercise behaviour. Exp Gerontol 2004; 39: 1347-1360.

20 Rodvold KA, Danziger LH, Gotfried MH. Steady-state plasma and bronchopulmonary concentrations of intravenous levofloxacin and azithromycin in healthy adults. Antimicrob Agents Chemother 2003; 47: 2450-2457.

21 Patel KB, Xuan D, Tessier PR, Russomanno JH, Quintiliani R, Nightingale CH. Comparison of bronchopulmonary pharmacokinetics of clarithromycin and azithromycin. Antimicrob Agents Chemother 1996; 40 2375-2379.

22 Gerhardt SG, McDyer JF, Girgis RE, Conte JV, Yang SC, Orens JB. Maintenance azithromycin therapy for bronchiolitis obliterans syndrome: results of a pilot study. Am J Respir Crit Care Med 2003; 168: 121-125.

23 Hand WL, Boozer RM, King-Thompson NL. Antibiotic uptake by alveolar macrophages of smokers. Antimicrob Agents Chemother 1985; 27: 42-45.

24 Labro MT. Anti-inflammatory activity of macrolides: a new therapeutic potential? J Antimicrob Chemother 1998; 41: Suppl. B, 37-46.

25 Tamaoki J. The effects of macrolides on inflammatory cells. Chest 2004; 125: Suppl. 2, 41S-50S.

26 Baumann U, King M, App EM, et al. Long term azithromycin therapy in cystic fibrosis patients: a study on drug levels and sputum properties. Can Respir J 2004; 11: 151-155.

27 Sakito O, Kadota J, Kohno S, Abe K, Shirai R, Hara K. Interleukin 1 beta, tumor necrosis factor alpha, and interleukin 8 in bronchoalveolar lavage fluid of patients with diffuse panbronchiolitis: a potential mechanism of macrolide therapy. Respiration 1996; 63: 42-48.

28 Culic O, Erakovic V, Cepelak I, et al. Azithromycin modulates neutrophil function and circulating inflammatory mediators in healthy human subjects. Eur J Pharmacol 2002; 450: 277-289.

29 Pletz MW, Ioanas M, de Roux A, Burkhardt O, Lode $\mathrm{H}$. Reduced spontaneous apoptosis in peripheral blood neutrophils during exacerbation of COPD. Eur Respir J 2004; 23: 532-537. 
30 Ohara T, Kojio S, Taneike I, et al. Effects of azithromycin on shiga toxin production by Escherichia coli and subsequent host inflammatory response. Antimicrob Agents Chemother 2002; 46: 3478-3483.

31 Savill J, Hogg N, Ren Y, Haslett C. Thrombospondin cooperates with CD36 and the vitronectin receptor in macrophage recognition of neutrophils undergoing apoptosis. J Clin Invest 1992; 90: 1513-1522.

32 Fadok VA, Bratton DL, Rose DM, Pearson A, Ezekewitz RA, Henson PM. A receptor for phosphatidylserine-specific clearance of apoptotic cells. Nature 2000; 405: 85-90.
33 Yamasawa H, Oshikawa K, Ohno S, Sugiyama Y. Macrolides inhibit epithelial cell-mediated neutrophil survival by modulating granulocyte macrophage colony-stimulating factor release. Am J Respir Cell Mol Biol 2004; 30: 569-575.

34 Rodvold KA, Gotfried MH, Danziger LH, Servi RJ. Intrapulmonary steady-state concentrations of clarithromycin and azithromycin in healthy adult volunteers. Antimicrob Agents Chemother 1997; 41: 1399-1402.

35 Banerjee D, Honeybourne D, Khair OA. The effect of oral clarithromycin on bronchial airway inflammation in moderate-to-severe stable COPD: a randomized controlled trial. Treat Respir Med 2004; 3: 59-65. 